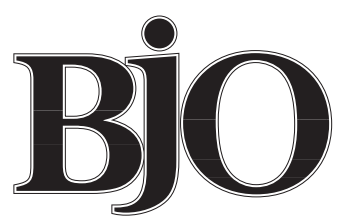

British Journal of Ophthalmology

As with any ophthalmic condition, the choice of which cataract procedure to employ must primarily be based upon clinical outcomes. However, given the status of cataract surgery as the most frequent, and therefore largest, overall procedural expenditure, the cost to the healthcare system should be considered as well. In their article in this issue of the $B F O$ ( $\mathrm{p}$ 822), Minassian and co-authors give us a definitive answer. This is a well designed prospective study in which eight experienced surgeons each performed equal numbers of phacoemulsification (Phako) and standard large incision extracapsular (ECCE) procedures; 500 patients were enrolled. Measured outcomes included uncorrected and best corrected visual acuity, astigmatism, intraoperative and postoperative complications, and cost.

A very important feature of this prospective study makes it unique in the cataract literature. The patients operated on by each surgeon were randomised between the two different procedures. This was necessary in order to avoid two potential and significant biases that would otherwise affect retrospective or non-randomised comparisons. Firstly, those surgeons primarily performing standard ECCE in recent years have tended to do a lower volume of surgery. ${ }^{1}$ Secondly, when surgeons regularly perform both procedures they tend to utilise standard ECCE for the more difficult and mature cataracts.

While numerous studies have documented the superiority of smaller incisions with respect to induced astigmatism and stabilisation of refraction, ${ }^{2-5}$ this randomised study demonstrated that Phako also resulted in better visual acuity and in fewer complications. Given the potential need for additional visits, medication, or surgery to manage complications this latter outcome alone would be expected to represent a significant cost advantage.

The reasons behind why Phako is safer are important to understand. The authors cite the smaller incision size as being one possible explanation. This would account for fewer wound complications and a decreased rate of intraoperative iris prolapse compared with the less watertight large ECCE incision. Surgical iris trauma can certainly cause intraoperative miosis and greater postoperative inflammation. Another important difference between the two procedures is the use of continuous curvilinear capsulorhexis (CCC) in Phako. Compared with a non-continuous type of capsulotomy, a CCC improves intraocular lens (IOL) centration and increases the resistance of the capsular bag to tearing during nuclear removal, cortical clean up, and IOL implantation. ${ }^{6}$

The most ambitious arm of the study is a comparative economic analysis of the two procedures. While at first glance one might expect Phako to be more expensive because of the surgical technology involved, the authors appropriately factor in costs beyond the operating room as well. In this study, the higher operating room expenses for Phako were offset by lower postoperative expenditures. As a result, the costs for the two procedures were comparable when tabulated several months postoperatively. However, extending the comparison to 6 or 12 months postoperatively gave the cost advantage to Phako because of fewer follow up visits, spectacle changes, and YAG capsulotomies.

Not surprisingly, the most common postoperative complication in this study was posterior capsule opacification. The reasons for the decreased rate of YAG capsulotomy in the Phako group are difficult to analyse because there are many variables involved. In this study, the Phako group received foldable silicone IOLs and the ECCE group received PMMA IOLs. Silicone IOLs are associated with lower rates of posterior capsule opacification compared with PMMA..$^{7-9}$ Another variable to consider is the capsulorhexis. Apple and others have shown that a capsulorhexis slightly smaller than, and therefore all "on" the optic, is associated with a decreased rate of posterior capsule opacification. ${ }^{10}{ }^{11}$

One can only speculate as to whether, and by how much, the cost advantage of Phako might have been underestimated by analysing data after one year instead of over a longer period of time. One would expect that the decreased long term refractive stability of a larger incision might result in more frequent refractions and spectacle changes over several years' time. ${ }^{4}{ }^{12}$ In addition, the YAG capsulotomy rate would probably rise within both groups over time, possibly further increasing the observed difference in incidence.

This study clearly demonstrates the overall superiority of Phako in the hands of experienced surgeons at two British teaching hospitals. It is important to realise, however, that the conclusions regarding cost and safety cannot be universally extrapolated to every healthcare setting. In Third World countries, for example, differences in surgical training, equipment, and in the incidence of mature cataracts might yield very different results. In fact "highly brunescent" cataracts were excluded from this particular study and it is unclear how inclusion of these cases might have affected the comparative outcomes. 
It is also difficult, based upon this study, to predict how another non-Phako ECCE procedure would fare. Manual small incision ECCE is a technique involving manual sectioning of the nucleus in order to allow smaller incisions and, in many cases, a capsulorhexis to be performed. ${ }^{13-16} \mathrm{~A}$ "low tech" procedure providing anatomic results more similar to those of Phako might produce a very favourable cost profile-particularly in the case of mature Third World cataracts.

Finally, beyond the comparisons of visual acuity, refractive error, complication rates, and cost that are presented in this study, we should also consider the perioperative experience of the patient - the so called "quality of life" issues. How much more do patients value a very rapid visual and physical rehabilitation following cataract surgery, and what is the economic cost of delays in this rehabilitation? To what extent might topical anaesthesia with minimal sedation favourably influence this experience? How much of an inconvenience is caused by the need for suture removal or YAG capsulotomy postoperatively? Much like in this important study, an evidence based approach can be used to analyse these questions as well. ${ }^{17}$ Along with efficacy, safety, and cost, this is a fourth factor to consider in deciding the procedure of choice for any operative condition.

Los Altos, California, USA

DAVID F CHANG

1 Leaming DV. Practice styles and preferences of ASCRS members-1993 Survey. F Cataract Refract Surg 1994;20:459-67.

2 Steinert RF, Brint SF, White SM, et al. Astigmatism after small incision cataract surgery; a prospective, randomized, multicenter comparison of 4and $6.5 \mathrm{~mm}$ incisions. Ophthalmology 1991;98:417-23.
3 Watson A, Sunderraj P. Comparison of small-incision phacoemulsification with standard extracapsular cataract surgery: post-operative astigmatism and visual recovery. Eye 1992;6:626-9.

4 Rainer G, Menapace R, Vass C, et al. Surgically induced astigmatism following a $4.0 \mathrm{~mm}$ sclerocorneal valve incision. F Cataract Refract Surg 1997;23:358-64.

5 Drews RC. Five year study of astigmatic stability after cataract surgery with intraocular lens implantation: comparison of wound sizes. 7 Cataract Refract Surg 2000;26:250-3.

6 Gimbel HV, Neuhann T. Development, advantages, and methods of the continuous circular capsulorhexis technique. $\mathcal{F}$ Cataract Refract Surg 1990; 16:31-7

7 Hollick EJ, Spalton DJ, Ursell PG. The effect of polymethylmethacrylate, silicone and polyacrylic intraocular lenses on posterior capsule opacification three years after cataract surgery. Ophthalmology 1999;106: 49-55.

8 Hayashi H, Hayashi K, Nakao F. Quantitative comparison of posterior capsule opacification after polymethylmethacrylate, silicone and soft acrylic intraocular lens implantation. Arch Ophthalmol 1998;116:1579-82.

9 Olson RJ. Is there truly a clinical difference in intraocular lenses available today? Comp Ophthalmol Update 2000;1:19-28.

10 Apple DJ, Peng Q, Visessook N, et al. Eradication of posterior capsule opacification. Ophthalmology 2001;108:505-18.

11 Peng Q, Visessook N, Apple DJ, et al. Surgical prevention of posterior capsule opacification. Part 3: Intraocular lens optic barrier effect as a second line of defense. F Cataract Refract Surg 2000;26:198-213.

12 Richards SC, Brodstein RS, Richards WL, et al. Long-term course of surgically induced astigmatism. F Cataract Refract Surg 1988;14:270-6.

13 Kansas PG, Sax R. Small incision cataract extraction and implantation surgery using a manual phacofragmentation technique. $\mathcal{F}$ Cataract Refract Surg 1988;14:328-30.

14 Blumenthal M, Ashkenazi I, Assia E, et al. Small-incision manual extracapsular cataract extraction using selective hydrodissection. Ophthalmic Surg 1992;23:699-701.

15 Mestres FD, Matheu A, Torres F, et al. Intraoperative complications of planned extracapsular cataract extraction versus manual nucleofragmentation. $\mathcal{F}$ Cataract Refract Surg 1996;22:1113-15.

16 Boyd BF. The small incision phaco section planned extracapsular manual technique. Highlights Ophthalmol 1997;25: 15-25.

17 Brown MM, Brown GC, Sharma S. The value component of evidencebased medicine. Cost-effective analysis: cataract surgery and sensitivity analysis. Evidence-Based Eye Care 2001;2:55-9.

\section{HAART, CMV retinitis, and monitoring}

With the advent of highly active antiretroviral therapy (HAART), the care of AIDS patients has drastically changed. Patients achieve partial immune reconstitution, appear capable of coming off medication and in many cases do not seem to have recurrences of cytomegalovirus (CMV). ${ }^{12}$ However, a risk period remains for the first few months after initiating HAART. ${ }^{3}$ The length of this period remains debatable, as does the best approach to monitor patients at risk

In their paper in this issue of the BFO ( $\mathrm{p} 837$ ), Zambarakji and colleagues have attempted to clarify these two issues. By reviewing longitudinally 1292 patients for their CD4 counts and HIV loads, they were able to show that recurrences and new lesions are more commonly observed in the first 6 months after starting HAART, and that after 12 months of therapy recurrences were not observed, even in patients with detectable HIV loads and low CD4 counts. While this confirms that sufficient immune reconstitution develops to prevent CMV retinitis some time after the first 6 months of HAART, the authors correctly state that their screening methodology is inadequate to identify patients at risk.

This last statement is of considerable importance for two reasons. Firstly, if an adequate screening methodology were available, only patients at risk for CMV retinitis during HAART induction would require follow up and treatment. Secondly, we would more easily identify patients, currently being treated with HAART, that are at risk for CMV retinitis. Cases of HAART resistance or noncompliance are increasingly being reported. A recent study suggested that for ritonavir and indinavir the rate of non-compliance with non-detectable serum drug levels was in the order of $12 \% .{ }^{4}$ Emergence of new resistant HIV strains occurs rapidly in patients failing HAART, requiring frequent therapy modifications.

Luckily, no significant increase in the incidence of CMV retinitis has yet been reported in this patient population, but an appropriate screening strategy is needed. With the current low incidence of CMV retinitis, such a strategy can only be developed by studying patients starting on HAART therapy. Understanding the factors leading to a specific immune reconstitution against CMV may pave the way to new monitoring strategies for patients at risk.

MARC D DE SMET

Department of Ophthalmology, University of Amsterdam Academic Medical Center, Amsterdam, Netherlands

1 Macdonald JC, Torriani FJ, Morse LS, et al. Lack of reactivation of cytomegalovirus (CMV) retinitis after stopping CMV maintenance therapy in AIDS patients with sustained elevations of CD4 $\mathrm{T}$ cells in response to highly active antiretroviral therapy. F Infect Dis 1998;177:1182-7.

2 Verbraak FD, Boom R, Wertheim-van Dillen PME, et al. Influence of highly active antiretroviral therapy (HAART) on the development of CMV disease active antiretroviral therapy (HAART) on the development of CMV disease
in HIV positive patients at high risk for CMV disease. Br 7 Ophthalmol in HIV positive

3 Van den Horn GJ, Meenken C, Danner SA, et al. Effects of protease inhibitors on the course of CMV retinitis in relation to CD4+ lymphocyte responses in HIV+ patients. Br f Ophthalmol 1998;82:988-90.

4 Murri R, Ammassari A, Gallicano K, et al. Patient-reported nonadherence to HAART is related to protease inhibitor levels. F Acquir Immun Def Syn 2000;24:123-8.

5 Paolucci S, Baldanti F, Maserati R, et al. Quantification of the impact of HIV-1 reverse transcriptase and protease mutations on the efficacy of rescue HAART. Antiviral Res 2000;45:101-14. 